\section{ECONOMICS}

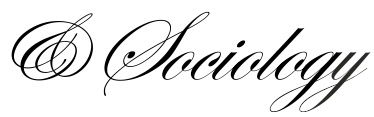

Adamska-Mieruszewska, J., Mrzygłód, U., Suchanek, M., \& FornalskaSkurczyńska, A. (2021). Keep it simple. The impact of language on crowdfunding success. Economics and Sociology, 14(1), 130-144. doi:10.14254/2071-789X.2021/14-1/9

\title{
KEEP IT SIMPLE. THE IMPACT OF LANGUAGE ON CROWDFUNDING SUCCESS
}

\author{
Joanna Adamska- \\ Mieruszewska \\ University of Gdansk, \\ Gdan'sk, Poland \\ E-mail: joanna.adamska- \\ mieruszewska@ug.edu.pl \\ ORCID 0000-0002-8138-4004
}

\author{
Urszula Mrzygłód \\ University of Gdanisk, \\ Gdańsk, Poland \\ E-mail:
}

urszula.mravglod@ug.edu.pl ORCID 0000-0003-4130-1494

\author{
Michał Suchanek \\ University of Gdańsk, \\ Gdansk, Poland \\ E-mail:
}

michal.suchanek@ug.edu.pl

ORCID 0000-0003-3506-6686

\author{
Anna Fornalska- \\ Skurczyńska \\ FH Krems, \\ Krems, Austria \\ E-mail:anna.fornalska@,fh- \\ krems.ac.at
}

ORCID 0000-0003-3066-2542

Received: February, 2020

1st Revision: June, 2020

Accepted: March, 2021

DOI: $10.14254 / 2071-$

789X.2021/14-1/9

JEL Classification: D26, G41, L21, L26, L31
ABSTRACT. The success of a crowdfunding campaign depends on obtaining funds provided by the online community. More precisely, the success of a campaign is defined as achieving its financial goal built upon convincing a relatively large number of people in a fundraiser's idea. Thus, efficient communication with "the crowd" is necessary to obtain its expected positive attitude change. In this respect, we argue that beyond the standard campaign features such as the number of supporters, the financing goal and the campaign duration, project's description becomes critical for a campaign's success. The goal of this paper is to investigate the relation between the readability, the length of a description and the funding success of a campaign in the reward-based crowdfunding model. Along with standard statistical measures, we conduct logit regression on the dataset comprising over 2800 projects published on one of the largest Polish crowdfunding platforms. Our results provide evidence that both description's length and text readability significantly influence the fundraising outcome. We interpret these results in the light of the persuasion effects as a longer text encompasses a higher number of arguments. Furthermore, a more detailed description decreases information asymmetry between the crowd and the project's author as well as induces the level of trust towards the latter. Finally, although the readability level of campaigns' descriptions in our sample is moderate, still the projects with a clearer description are preferred by the online community.

Keywords: crowdfunding, text readability, crowdfunding campaign, success determinants, Poland. 


\section{Introduction}

Crowdfunding is an innovative segment of the financial market providing funds for individual, business, social, cultural and charity-oriented projects. It is a form of community financing, where a large group of supporters is contributing relatively small cash payments in exchange for rewards, recognition or a share in a company. Crowdfunding provides access to capital for small and medium enterprises, start-ups and individuals. However, the benefits for projects' authors go beyond just financing. Crowdfunding acts as a good marketing tool within an online community. Notwithstanding it helps to establish relations with potential clients, investors, media or business partners. It also provides the proof of market fit and allows preselling. The noticeable economic gain that can be achieved through this non-traditional financing scheme, especially by small entrepreneurs, has contributed in recent years to its exponential growth. The global alternative finance market, including different crowdfunding models, reached the volume of USD 304,5 bln in 2018, which means an outstanding increase from USD 139 bln in 2015 (Ziegler et al., 2020).

In the reward-based crowdfunding, quality of communication with potential backers becomes critical for a campaign's success. In particular, the fundraising process is performed entirely online. Therefore, it is important to the project owner to attract attention and gain the trust of many individual supporters. Moreover, by the very nature of the model, the vast majority of projects' supporters are not professionals in the field of finance, contrary to the equity market, where professional and institutional investors constitute a significant group.

Efficient communication in crowdfunding should, therefore, concentrate on building a network within the crowd, not just relation with a particular entity, as it is in the relationship finance in banking. Furthermore, in the reward-based crowdfunding, communication with potential supporters is not strictly formalized. Although the majority of platforms aim to unify the structure of campaign, contents and the level of information disclosure depends solely on a project's author. Unlike in an IPO transaction, there are no formal regulatory mechanisms specifying the scope of the supplied information or the designated financial intermediaries. Besides, in crowdfunding, communication channels between the project's author and potential supporters are often limited to the web. In crowdfunding, an entrepreneur is a storyteller, and the story he/she tells influences the scope of the support attracted to the venture (Luo \& Luo, 2017). Creating a compelling narrative plays a crucial role in convincing potential backers to support a project. We believe that a proper campaign design, together with project description, and skilful communication within the network are inevitable to achieve the fundraising goal. The determinants of crowdfunding success are related to users' subjective opinions and their perception of campaigns. Thus, project's description, its quality, and structure may be perceived as important marketing tools which also reduce information asymmetry and influence potential supporters' decision to fund a project. Project description is not only a primary source of information for the potential project's backers, but it is also an important communication tool between the project's author(s) and supporters.

Due to the fact that we focus on project description which is created before the campaign is launched and remains unchanged until the end of the project, we refer to the one-way model of communication between the project's author(s) and project's supporters. The two-way communication via comments and responding to them is not the subject of our analysis. Thus, in this study, we interpret communication between fundraisers and supporters as a unidirectional mass persuasion process. In this aspect, we draw upon Lasswell's (1948) model of persuasion which, despite its uncomplicated nature and linearity, skilfully captures the nature of mass communication on the internet (Makowski, 2013, p. 60-61).

Guided by the theory of persuasion we identify two groups of potential crowdfunding success determinants related to the project's description. Therefore, our research model 
includes two dimensions: information quantity (number of words, sentences, and paragraphs) and information quality (text readability). Since the projects' characteristics (funding goal, duration and the number of supporters) have been identified as crowdfunding success determinants in previous researches, we treat them as the control variables. The goal of this paper is to investigate the relation between the readability and the length of the project's description and the funding success of the campaign in the reward-based crowdfunding model. We study the relation between the language used in the project's description and the crowdfunding success with the use of logistic regression. It is an important problem rarely analyzed in research on crowdfunding. This study contributes to the understanding of linguistic dimension of crowdfunding campaigns, which is an important problem, however scarcily present in the literature.

There are several reasons that make descriptions in Polish particularly interesting for research. Firstly, Polish grammar is considerably different from English which stems from diverging origins of both languages and distinct groups of the Indo-European languages. The grammatical functions of word forms in Polish manifest itself not by their place in the sentence (word order), but by their inflectional affixes (e.g. suffixes), (Bańko, 2009, p. 210-219). Secondly, the word order in Polish enables to highlight the hierarchy of content (old versus new information). In comparison, English is a language with a poor inflection and a relatively constant word order. To the best of our knowledge this paper is among the first to explore the relation between language antecedents and crowdfunding success in a language different than English.

This paper is structured as follows: A literature review of the impact of the crowdfunding campaign's description on the project's success as well as the theory of persuasion is presented in Section1; the sample that was used in the empirical analysis and research design arediscussed in Section 2; the research design and findings of this study are discussed in Section 3 and at the end of the paper conclusions and implications for further research are presented.

\section{Literature review and hypothesis development}

The phenomenon of crowdfunding is gaining the increasing interest of researchers, especially regarding the success' determinants. The literature on crowdfunding success can be classified into two categories. The first one concentrates on the projects' authors, their social network and the ability to attract potential supporters. These variables can be expressed in the number of updates uploaded by the initiator, comments left by supporters, the number of Facebook friends, as well as the author's previous experience in crowdfunding (Mollick, 2014, Beier \& Wagner, 2015, Colombo et al., 2015, Agrawal et al., 2011, Wang et al., (2018) Mrzygłód et al., 2018; Kuppuswamy \& Bayus, 2017; Mollick, 2014). The in-depth systematic literature review of the success factors is provided by Shneor and Vik (2020). The second stream of literature focuses on campaign's characteristics, such as the financing goal, the duration of the campaign, as well as the number of supporters (Mollick, 2014; Cordova et al., 2015).

The funding goal set by the creator of the campaign should allow the project to be successfully created. However, deciding on a value that is too high might undermine the project as the probability of the campaign success is negatively related to the target capital (Mollick, 2014; Colombo et al., 2015, Cordova et al., 2015). The higher the goal the lower the probability of reaching it. This has been further proven for specific categories of projects such as design or music (Cruz, 2018). In fact, the value of the project goal is often introduced as control variables in probit and logit regression models used for the analysis of the crowdfunding success (Wang et al., 2018). 
Furthermore, the duration of the project campaign on crowdfunding platforms is fairly unanimous (Mollick, 2014). Thirty days is the most common length of the project campaign at Kickstarter (Kuppuswamy \& Bayus, 2017). The specific dynamics of crowdfunding means that prolonging the duration of the campaign does not necessarily increase its funding. Whereas the intensity of the campaign in its early days is crucial, the overall duration of the campaign proved not to be a statistically significant predictor of the campaign success in a probit model (Colombo et al., 2015). However, there has been some research pointing out to the opposite, proving that the longer duration of the project leads to more opportunities for receiving capital and thus a higher probability of success (Cordova et al., 2015).

Finally, the number of supporters and backers is the most common factor in the success of the crowdfunding campaign as it directly impacts the volume of funds gathered and also provides publicity for the project (Vukovic et al., 2009; Kazai, 2011; Colombo et al., 2015). It has been proven that the number of supporters is the most important condition for a high funding level of the project regardless of other factors. They provide the cash flow necessary for the upkeep of the project and also serve as proof of the public interest in the project (Kraus et al., 2016).

Although the prior research contributes greatly to the understanding of crowdfunding determinants, only a few studies, have focused on the project's description. Nonetheless, the importance of text as a success driver of the campaign is discussed Zhao and Ryu (2020). The language used in the crowdfunding campaigns has been investigated in the recent research of Mitra and Gilbert (2014), Zhou et al. (2018). Altogether, these papers stress the importance of the project's description features (i.e. a number of words), as well as a proper narration and language readability in explaining the fundraising success.

The process of speaking forces the interlocutors to deliver the message faster than in the case of the written statement (Bartmiński \&Niebrzegowska-Bartmińska 2010, pp. 105, 107 108). Therefore, the written text is often (but not always) more precise, grammatically correct and thoroughly planned. However, as Bartmiński and Niebrzegowska-Bartmińska (2010, p. 109) indicate, in the written text the situational background of the message disappears and raises additional difficulties for the writer to resemble the desired context. Moreover, as the recipient of the message does not look over the writer's shoulder, sometimes she becomes forgotten. Thus, it may happen that the text does not contain convincing arguments, is needlessly complicated and finally loses its persuasive power. Following the Lasswell's reasoning, a project description is a tool in which persuasive content (argumentation) is conveyed. We also profit largely from the unimodal model of persuasion which is based on the Kruglanski's (1989, 2004) lay-epistemic theory of knowledge formation. Contrary to dual models, the unimodal persuasion concept assumes that all epistemic questions are carried out within the same judgmental process. One of the first on the subject is the paper by Mitra and Gilbert (2014). The authors analyze words and phrases used in the descriptions of the crowdfunding projects and notice that the language used in the project's description of Kickstarters' campaigns has a strong predictive power. Mitra and Gilbert (2014) point out that selected phrases used in the project's description are in line with the general persuasion principles and significantly influence campaign's success. An interesting research on the relation between the phrases used in the projects' description and the success of the crowdfunding campaign is proposed by Pietraszkiewicz et al. (2017). The study focuses on the prosocial motivation of campaigns' authors determined by the specific language used in the project description. Pietraszkiewicz et al. (2017) argue that more frequent use of a particular set of words related to prosocial behavior has a significant influence on the success of the campaign. They notice that a higher percentage of prosocial words in the project's description positively affects campaign funding and a number of supporters, as backer tend to prefer projects with social goals. Both papers depict the phrases of prosocial or persuasive character that influence the supporters' decision to contribute. 
However, they do not provide general overview of the impact of the crowdfunding campaign description's complexity and readability on the funding success. Wang et al. (2020) investigate the influence of text narratives on the success of crowdfunding campaigns by examining textual sources including titles, blurbs and descriptions using the text content emphasis (TCE) detection approach. They find that the profile of the entrepreneur should be emphasized in the title and at the beginning of the project description. The idea itself might be introduced later on in the detailed description. Tafesse (2021) concentrates on crowdfunding campaigns communication strategies and their impact on the project's success. An interesting finding is that incorporating positive emotions into communication process does not necessarily contribute to the success, as it might be perceived as a distraction by the backers.

Regarding the text complexity and readability, prior studies indicated a variety of factors, e.g. vocabulary used, the structure of the sentence or its length (Charzyńska et al. 2015). The diversity of modern languages is related to the development process of society and culture. Following Wierzbicka (1997 p. 1-2) we can say that culture manifests itself via the existence of unique words in the lexicon reflecting specific customs, institutions or types of food. In her earlier study Wierzbicka (1985) argues that varied cultural norms are reflected in the speech acts of the same language expressed by people from different regions of the same country. Moreover, Wierzbicka (1985) denotes an ethnocentric bias within English linguistic studies which leads to excessively general conclusions and may not hold in other languages. Therefore, with this paper, we seek to address this gap by presenting a perspective into understanding the impact of Polish language used in the crowdfunding campaigns on the fundraising outcome.

Since the 1920's the researchers have proposed numerous readability formulas and in the vast majority of cases, they are based on syntactic and semantic complexity. Usually, syntactic complexity is described by the number of words per sentence, whereas semantic complexity by the word familiarity or a number of syllables per word (Hiebert 2011, p. 3). Dębowski et al. (2015, p. 52) present a general overview of the evolution of scientific interest in linguistic text analysis. Lively and Pressey (1923), Vogel and Washburne (1928) and Patty and Painter (1931) used text statistics to measure its readability. But it was in the 1940s (Lorge 1944; Flesch 1948) when it was observed that two basic statistics (ASL and AWL) suffice to predict the readability of the text. ASL is the average sentence length, whereas AWL the average word length. Gunning (1952) is an author of a widely recognized FOG index that takes into consideration the ASL and PHW, where PHW stands for the percentage of words longer than two syllables. Those formulas were an inspiration for the other researchers in designing tools depicting the readability of the text, such as relatively simple lix (Björnsson, 1983) or complex Jasnopis.pl measures.

An interesting study in which the authors adapted readability measures to the crowdfunding, is the paper by Lagazio and Querci (2018). The researchers analyze the success determinants of the Italian crowdfunding campaigns and notice that the length of a text description, measured by using more than 500 words increases the probability of reaching the funding goal by $13 \%$ in comparison to the projects with the description shorter than 200 words. Similar results were obtained by Koch and Siering (2015), who notice, that the amount of information published is positively related to the crowdfunding success. Authors point out, that the length of the description lowers information asymmetry between project's author and its potential supporters. An interesting contribution to the presented problem is made by Moy et al. (2018). The authors examine the effects of the length of the project's description on the crowdfunding performance. Moy et. al (2018) notice that the relation between campaign's text length and the funding success is U-shaped, suggesting there is an optimal number of words in the crowdfunding campaign and beyond it potential supporters feel overloaded with information. 
Regarding the quality dimensions of the crowdfunding projects description, an interesting study was proposed by Zhou et al. (2016). The authors based their analysis on the unimodel theory of persuasion and identified two types of antecedents of funding success: the content of the project's description (issue relevant factors) and the trustworthy cue (issue irrelevant factors). Authors notice that the relation between the readability of the description and the success is positive, which may suggest that formally written projects are perceived as a signal of project's owner's professionalism. Zhou et al. (2014) claim, that more complex description may be prepared by more professional authors gaining more trust among supporters (Zhou et al. 2016). On the contrary, Xu et. al (2014) analyzed the readability of crowdfunding campaign's updates and noticed that easier language used increases crowd participation and thus the chances of funding the project. Similarly, Pancer et al. (2018) suggest that readability is important for consumer engagement in social media, since often as little as seconds are spent on reading a post. We believe that a similar assumption can be made for the crowdfunding project description in the reward-based model.

The theoretical basis for studying the impact of project description on the fundraising outcome has its roots in the persuasion theory. Being persuaded means that our behavior or attitudes have been influenced by a certain persuasive message. Petty and Briñol (2010, p. 217) indicate that persuasion deals with any action that influences someone's attitude. If the persuasion process is meant to occur it must be preceded by the act of communication. According to the McGuire process of persuasion $(1968,1985)$ to receive the persuasive message the recipient must not only focus his attention but also be able to comprehend. It means that the sender of the message must take into account the receivers' abilities (Wojciszke, 2002, p. 20122013).

In the case of crowdfunding, the fundraiser must rely on the project description, which implies the mass character of the communication process. According to Lasswell (1948) the act of communication is deconstructed into the following components: communicator, message channel, audience and effect. This model skillfully captures the nature of mass communication on the Internet (Makowski, 2013, p. 60-61). Moreover, the psychological theories of persuasion that gained interest in contemporary research are those emphasising the dual-mode (elaboration likelihood model) or single-mode (unimodal theory) of this process.

Following the Petty and Cacioppo's (1986) elaboration likelihood model (ELM), the attitude change can be achieved with two distinct routes, namely central and peripheral processing. Within the central route, the individuals are able to receive the message i.e. are motivated and have cognitive ability to do so. Thus, in the central route the persuasion is thoughtful in nature and implies the usage of the strong arguments. The persuasion process in the peripheral route is influenced by simple cues (heuristics), while individuals are motivated or able to process more complex argumentation (Petty \& Briñol 2010, p. 233). On the contrary, the single mode theory of persuasion, is based on the Kruglanski's $(1989,2004)$ lay-epistemic theory of knowledge formation and assumes that all epistemic questions are carried out within the same judgmental process (Kruglanski et al., 2006). Thus, all information, irrespective of its relevance (issue-relevant or issue-irrelevant) is processed within the same route (Zhou et al., 2018).

The text description is one of the main sources of information about the crowdfunding project. Thus, we assume, that providing detailed data about the projects reduces the information asymmetry, raises trust toward the fundraiser, and leads to a higher willingness to support. Campaigns with a larger number of arguments in the description are therefore having higher chances of funding success. Thus, this paper tests the following hypothesis:

H1: The length of the text, measured by the number of words, sentences and paragraphs, is positively related to the crowdfunding success in the reward-based model. 
Apart from the quantity dimension of the crowdfunding campaigns' description, we believe that what also influences the funding success is the quality of text measured by its readability. The problem of the text readability significance in finance is widely discussed in the literature, especially in the area of the annual reports. One of the first papers on the topic was the article by Poshalian and Crissy (1952). Authors notice that 75 percent of analyzed annual report are too difficult and include too many long sentences and many-syllable words. However, it is worth emphasizing, that the target group of annual financial reports is usually more experienced in the field of finance. In the reward-based crowdfunding, the target group usually does not include professionals. Moreover, the success is usually determined by the number of small contributions made by the online community. Thus, the decision of the majority of supporters is related to emotions the campaign evokes. The text readability is, therefore, one of the main tools of persuasion. Consequently, in line with the theory of persuasion, we assume:

H2: The readability of the crowdfunding project's description is positively related to the crowdfunding success in the reward-based model.

\section{Methodological approach}

In this study we employed two sources of data. First, we collected detailed information about 3218 crowdfunding campaigns organised through the PolakPotrafi.pl platform within the time span of March 2011 to May 2018. Contrary to other papers designed in Poland, our dataset covers also the projects that were not successful in obtaining the required amount of money. More specifically we gathered information about the starting and the ending date of the campaign, the addressed as well as the collected amount and the number of people that supported the campaign financially. This enabled us to construct the dependent variables and three control ones. For each of the campaigns we calculated the level of success ratio (SR) by comparing the collected amount to the financial goal of the campaign (target), according to the following formula:

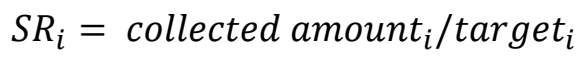

Then we defined the ordinal variable SUCCESS in the following form:

$$
\operatorname{SUCCESS~}_{i}=\left\{\begin{array}{c}
0 \text { if } S R_{i}<1 \\
1 \text { if } 1 \leq S R_{i} \leq 1.1 \\
2 \text { if } S R_{i}>1.1
\end{array}\right.
$$

Thus, the depending variable SUCCESS takes the value of zero if the project did not reach the financial goal. This reflects all-or-nothing character of the PolakPotrafi.pl platform. Moreover, drawing on former studies, among projects that received the necessary funding, we distinguished those that collected more than 110 percent of the required amount. The value of the dependent variable for these projects was set at two. The introduced threshold stays in line with the fact that successful campaigns are overfunded only by small margins above the requested target (Mollick, 2014). As for the control variables, we took the required amount (TARGET) and a number of campaign's supporters (SUPP.NO), both expressed in natural logarithms. Finally, following other studies (Colombo et al. 2015, Cordova et al. 2015, Kuppuswamy \& Bayus, 2017), we also included DURMONTH, which denotes the duration of the campaign expressed in months (table 1). 
Table 1. Description of variables

\begin{tabular}{ll}
\hline Variable & Definition \\
\hline target & the amount the owner seeks to raise (thousands of PLN, ln) \\
\hline durmonth & the length of project' funding campaign (in months) \\
\hline supp.no & the number of backers supporting the project (ln) \\
\hline fogtxt & word form given in the text \\
\hline fogdct & dictionary-based word form \\
\hline fogr & words which are not widely known \\
\hline nword & the length of the text in words (ln) \\
\hline nparag & number of paragraphs in the text (ln) \\
\hline nsent & number of sentences in the text (ln) \\
\hline dfwords & number of difficult words in the text (ln) \\
\hline class & the index describing the difficulty of the project's description in the scale 1-7, \\
& where 1 means the easiest description
\end{tabular}

Source: Own compilation

Second, we enriched the dataset with linguistic features as well as the readability of the campaign's description (table 1). Here, we profited largely from Jasnopis.pl (Jasnopis.pl), which is an IT tool, created to evaluate Polish non-literary texts with respect to their clarity and the level of difficulty ( Gruszczyński et al., 2014, p. 573).

We expressed the linguistic data in natural logarithms and our first variable employed is CLASS, which originally in Jasnpopis.pl measures the text difficulty on the scale 1-7, which corresponds to the levels of education necessary to be finished in order understand the text; "One" is attributed to the least complicated texts (age 6-9, primary school) whereas texts which get a score of "seven" are assumed to be the most complicated ones, which can be easily read and understood mainly by specialists of the given field (people with specialist knowledge of the topic and connected vocabulary, such as: graduates of postgraduate studies, $\mathrm{PhD}$, experts in the field). Next, variables employed are FOGTXT, FOGDCT, and FOGR, which correspond to the Gunning fog index (Charzyńska et al., 2015, p. 14-15). Similarly to the original idea, indices in the Jasnopis.pl tool, are determined by the number of difficult words in the text. In the Polish adaptation, however a word having four or more syllables is defined as a 'difficult word', whereas for English it is three syllables. We decided to employ three versions of the index readability calculated by Jasnopis.pl, which refer to the word form given in the text (FOGTXT), dictionary-based word form (FOGDCT), and words which are not widely known (FOGR). Finally, we also considered the length of the text in words (NWORD), number of paragraphs (NPARAG) and sentences (NSENT) and the number of difficult words (DFWORDS). Again, these variables were expressed in natural logarithms.

The collected dataset went through a preliminary inspection. First, after a manual check on the corresponding websites, 38 projects with incomplete basic information were removed from the sample. Second, we decided to eliminate 346 projects with the number of words lower than 400 in the description. This condition was set after further investigation of the websites, which revealed frequent usage of infographics instead of plain text and disturbed the obtained text readiness measures on Jasnopis.pl. Overall, our effort in data collection and inspection resulted in 2835 projects. The data was collected in June 2018 and it includes all the projects appearing on the Polakpotrafi.pl website since its start in March 2011 up until the end of May 2018, as indicated above.

To verify hypotheses, we apply the sequential ordered logit model, which is also called continuation ratio model. These models effectively capture the nature of our dependent variable, which represent successive stages in collecting money through crowdfunding campaign. In all specifications we control for the campaign's main characteristics (TARGET, SUPP.NO and 
DURMONTH). Next, we interchangeably include the variables of our interest in regression (CLASS, FOGTXT, FOGDCT, FOGR, NWORD, NPARAG, NSENT, DFWORDS). Although linguistic variables are not identically distributed, the correlation coefficients between them are at least moderate, which justifies the applied procedure.

Finally, for the robustness check we also ran the regressions with other readability indices from Jasnopis.pl, which were developed by Pisarek in the 1960s for the Polish language (in linear and non-linear form). While robustness check did not differ significantly from the basic results, it is not included in the text for greater clarity of argumentation. It is however available upon request.

\section{Conducting research and results}

Table 2 presents the descriptive statistics of the primary data used in the analysis. The average success rate of our sample projects is $47 \%$. The average target value requested by the project's author is PLN 12,555 PLN (about EUR 3,000), however half of the projects set a goal lower than PLN 7,000 (EUR 1,600).

Table 2. Descriptive statistics

\begin{tabular}{lllllll}
\hline Variable & Min & 1st Q & Mean & Median & 3rd Q & Max \\
\hline target & 105 & 3762.5 & 12550.05 & 7000 & 14000 & 2000000 \\
\hline durmonth & 0.03 & 1 & 1.33 & 1.33 & 1.5 & 9.57 \\
\hline supp.no & 1 & 13 & 69.70 & 35 & 79 & 3688 \\
\hline fogtxt & 5.68 & 10.67 & 11.72 & 11.68 & 12.7 & 19.31 \\
\hline fogdct & 4.98 & 9.14 & 10.06 & 9.99 & 10.9 & 16.96 \\
\hline fogr & 3.69 & 6.53 & 7.22 & 7.13 & 7.82 & 13.25 \\
\hline nword & 400 & 614 & 958.08 & 809 & 1152 & 8287 \\
\hline nparag & 3 & 14 & 24.12 & 21 & 29 & 226 \\
\hline nsent & 21 & 44 & 70.54 & 59 & 84 & 1154 \\
\hline dfwords & 11 & 24 & 38.10 & 32 & 45 & 239 \\
\hline class & 2 & 4 & 4.30 & 4 & 5 & 7 \\
\hline Due & & & & & &
\end{tabular}

Due to the text readability, the table presents the descriptive statistics of the original data (i.e. the variables have not been expressed in natural logarithms).

Source: Own calculations in Statistica

On average, each project was supported by almost 70 backers but half of the projects gained the attention of fewer than 35 supporters. The average campaign duration is 1.33 months. Regarding the language antecedents, the average length of the project description is 950 words (median: 809), 24 paragraphs and 70 sentences. The median text class of the projects in the sample is 4 with the mean value of 4.30 , which means that the text is slightly more difficult but comprehensible to people with secondary education. The maximum text class of the campaigns in the sample is 7 , that coincides with the maximum value of the index, however, there is only one such a project in the sample. 
Table 3. Variables median values by separate categories of crowdfunding projects

\begin{tabular}{lllllllllllll}
\hline Category & $\mathrm{N}$ & Target & $\begin{array}{l}\text { durn } \\
\text { month }\end{array}$ & $\begin{array}{l}\text { supp. } \\
\text { no }\end{array}$ & $\begin{array}{l}\text { fog } \\
\text { txt }\end{array}$ & $\begin{array}{l}\text { fog } \\
\text { dct }\end{array}$ & fogr & $\begin{array}{l}\mathrm{n} \\
\text { word }\end{array}$ & nparag & nsent & dfwords & class \\
\hline arts & 104 & 6000 & 1.2 & 40.5 & 12.1 & 10.5 & 7.3 & 803.0 & 18.0 & 58.0 & 35.0 & 5.0 \\
\hline books & 358 & 7350 & 1.5 & 33.0 & 10.9 & 9.4 & 6.8 & 912.0 & 22.0 & 70.0 & 33.0 & 4.0 \\
\hline comics & 66 & 5000 & 1.1 & 29.0 & 12.4 & 10.5 & 7.4 & 711.0 & 17.0 & 52.0 & 29.0 & 5.0 \\
\hline dance & 12 & 7000 & 1.4 & 55.5 & 11.7 & 9.9 & 7.3 & 608.5 & 12.5 & 44.0 & 24.5 & 4.0 \\
\hline design & 35 & 9500 & 1.5 & 37.0 & 11.5 & 9.9 & 7.3 & 764.0 & 21.0 & 59.0 & 37.0 & 4.0 \\
\hline education & 196 & 9000 & 1.5 & 25.5 & 12.4 & 10.6 & 7.4 & 815.5 & 21.0 & 57.5 & 34.0 & 4.0 \\
\hline events & 202 & 5000 & 1.0 & 29.0 & 12.4 & 10.6 & 7.3 & 772.5 & 19.0 & 54.5 & 31.0 & 5.0 \\
\hline fashion & 16 & 6990 & 1.2 & 12.0 & 11.4 & 10.1 & 7.3 & 630.0 & 17.0 & 48.5 & 25.5 & 4.0 \\
\hline food & 37 & 5500 & 1.1 & 39.0 & 11.9 & 10.2 & 7.1 & 664.0 & 17.0 & 46.0 & 25.0 & 5.0 \\
\hline photography & 39 & 7000 & 1.0 & 44.0 & 12.7 & 10.7 & 7.3 & 752.0 & 19.0 & 53.0 & 32.0 & 5.0 \\
\hline games & 50 & 6500 & 1.5 & 25.0 & 11.1 & 9.8 & 7.2 & 842.5 & 23.0 & 60.0 & 35.0 & 4.0 \\
\hline journalism & 33 & 7000 & 1.5 & 26.0 & 11.8 & 10.1 & 7.0 & 832.0 & 20.0 & 62.0 & 32.0 & 4.0 \\
\hline journeys & 261 & 5500 & 1.3 & 34.0 & 11.3 & 9.5 & 7.0 & 876.0 & 21.0 & 63.0 & 30.0 & 4.0 \\
\hline music & 413 & 6500 & 1.5 & 52.0 & 11.4 & 9.9 & 7.1 & 718.0 & 18.0 & 54.0 & 30.0 & 4.0 \\
\hline social & 220 & 8000 & 1.3 & 39.0 & 12.0 & 10.3 & 7.3 & 839.5 & 23.0 & 62.5 & 34.0 & 4.0 \\
\hline sport & 289 & 10000 & 1.2 & 50.0 & 11.3 & 9.7 & 6.9 & 835.0 & 22.0 & 60.0 & 29.0 & 4.0 \\
\hline technology & 128 & 9949.5 & 1.5 & 16.0 & 12.6 & 10.8 & 7.6 & 781.0 & 19.0 & 56.0 & 35.5 & 4.0 \\
\hline theater & 24 & 11750 & 1.5 & 32.5 & 11.5 & 10.0 & 7.1 & 847.5 & 29.0 & 66.0 & 32.0 & 4.0 \\
\hline video & 279 & 7000.0 & 1.3 & 34.0 & 11.7 & 9.9 & 7.1 & 905.0 & 22.0 & 68.0 & 39.0 & 4.0 \\
\hline others & 73 & 5600.0 & 1.5 & 25.0 & 11.7 & 10.0 & 7.2 & 786.0 & 19.0 & 61.0 & 33.0 & 4.0 \\
\hline a & & & & & & & & & &
\end{tabular}

${ }^{a}$ as in table 2.

Source: Own calculations in Statistica

Additionally, 49 projects are classified as difficult to understand. It means that the overall readability is high and the language used in the crowdfunding campaigns is not very complex, thus projects' description is relatively easy to understand. Similar conclusions can be derived from the analysis of the Polish adaptation of the Gunning fog index. In three versions of this index, the mean and median values suggest that the project descriptions are easy to understand (with the average value of the FOG text version index of 11.7). Possible explanations is that in comparison to business plans presented in IPO or loan application, crowdfunding projects are more likely to be presented in an informal way. On the PolakPotrafi platform, crowdfunding campaigns are classified into 20 categories. Table 3 presents the median values of antecedents analyzed in the paper, by categories. The target amount, as well as the number of supporters, differ significantly, reflecting the different popularity and types of projects among categories. Projects that gained the attention of the largest number of supporters are those reported in categories dance, music, and sport, while less popular projects are those classified in technology and fashion. Regarding the language antecedents, the longest description was in projects reported in the video and books category, while more difficult language was used in photography and technology. The possible reason is that the specificity of these categories involves the use of professional language.

Additionally, we conducted Kolmogorov-Smirnov and U Mann-Whitney tests to check for the statistical differences between successful and unsuccessful crowdfunding projects. These calculations have been also done on the primary data. The obtained results, presented in the table 4, indicate that successful and unsuccessful projects differ significantly in both control variables and language antecedents. In the analysed sample, only two variables do not differ significantly for projects that have obtained funding and those that have failed: the text difficulty index (class) and the FOG index including not widely known words (FOGR). 
Table 4. The comparison of funded and non-funded crowdfunding projects - differences tests

\begin{tabular}{lll}
\hline Variable & U Mann-Whitney (p-value) & Kolmogorov-Smirnov (p-value) \\
\hline target & 0.0000 & $\mathrm{p}<.001$ \\
\hline durmonth & 0.0000 & $\mathrm{p}<.001$ \\
\hline supp.no & 0.0000 & $\mathrm{p}<.001$ \\
\hline fogtxt & 0.0050 & $\mathrm{p}<.025$ \\
\hline fogdct & 0.0233 & $\mathrm{p}<.05$ \\
\hline fogr & 0.1131 & $\mathrm{p}<.025$ \\
\hline nwords & 0.0002 & $\mathrm{p}<.005$ \\
\hline nparag & 0.0000 & $\mathrm{p}<.001$ \\
\hline nsent & 0.0000 & $\mathrm{p}<.005$ \\
\hline dfwords & 0.0002 & $\mathrm{p}<.025$ \\
\hline class & 0.4431 & $\mathrm{p}>.10$
\end{tabular}

Source: Own calculations in Statistica

In the Table 5, we report the results of the logit regressions. In all specifications, we employ the same control variables: target amount, number of supporters and campaigns' duration in months. We report variable coefficients, standard errors (in brackets) and the postestimation checks for each specification. In the first specification (Model 1) we included the control variables only. The target amount and the number of supporters are statistically significant and gained the expected sign. In line with the literature, the number of supporters positively impacts funding success whereas the target amount is negatively related to success. Surprisingly, the results for the project's duration are statistically significant but have the opposite sign than expected. Contrary to previous studies, in our sample, the longer campaign decreases the chance of obtaining the funding. The observed specificity in crowdfunding duration for Polish campaigns may be explained by the low trust in Polish society. Long campaigns may be perceived as a result of the author's uncertainty concerning the project. The results of the control variables are consistent in models 1-8.

Table 5. Estimation results

\begin{tabular}{|c|c|c|c|c|c|c|c|c|}
\hline Variable & Model 1 & Model 2 & Model 3 & Model 4 & Model 5 & Model 6 & Model 7 & Model 8 \\
\hline target & $\begin{array}{l}-1.3146 * * * * \\
{[.0543]}\end{array}$ & $\begin{array}{l}-1.3141 * * * \\
{[.0543]}\end{array}$ & $\begin{array}{l}-1.3194 * * * * \\
{[.0545]}\end{array}$ & $\begin{array}{l}-1.3179 \text { *** } \\
{[.0544]}\end{array}$ & $\begin{array}{l}-1.3162 * * * \\
{[.05438]}\end{array}$ & $\begin{array}{l}-1.3542 * * * \\
{[.05587]}\end{array}$ & $\begin{array}{l}-1.3479 * * * \\
{[.05568]}\end{array}$ & $\begin{array}{l}- \\
1.3427 * * * \\
{[.05565]}\end{array}$ \\
\hline supp.no & $\begin{array}{l}.3239 * * * \\
{[.0115]} \\
\end{array}$ & $\begin{array}{l}.3238 * * * \\
{[.01154]} \\
\end{array}$ & $\begin{array}{l}.3234 * * * \\
{[.01154]} \\
\end{array}$ & $\begin{array}{l}.3233^{* * * *} \\
{[.0115]}\end{array}$ & $\begin{array}{l}.3239 * * * \\
{[.0115]} \\
\end{array}$ & $\begin{array}{l}.3208 * * * \\
{[.01155]} \\
\end{array}$ & $\begin{array}{l}.3208 * * * \\
{[.01156]} \\
\end{array}$ & $\begin{array}{l}.3212 * * * \\
{[.0116]} \\
\end{array}$ \\
\hline durmonth & $\begin{array}{l}.2694 * * * \\
{[.0851]} \\
\end{array}$ & $\begin{array}{l}.2718 * * * \\
{[.0853]} \\
\end{array}$ & $\begin{array}{l}.2732 * * * \\
{[.0855]}\end{array}$ & $\begin{array}{l}-.2733 * * * \\
{[.0855]} \\
\end{array}$ & $\begin{array}{l}.2663 * * * \\
{[.0853]} \\
\end{array}$ & $\begin{array}{l}-.2559 * * * \\
{[.0859]} \\
\end{array}$ & $\begin{array}{l}.2644 * * * \\
{[.0856]} \\
\end{array}$ & $\begin{array}{l}.2668 * * * \\
{[.0855]} \\
\end{array}$ \\
\hline class & & $\begin{array}{l}-.1399 \\
{[.2429]} \\
\end{array}$ & & & & & & \\
\hline fogtxt & & & & $\begin{array}{l}-.7041 * * \\
{[.2924]} \\
\end{array}$ & & & & \\
\hline fogdct & & & $\begin{array}{l}.65377 * \\
{[.2856]} \\
\end{array}$ & & & & & \\
\hline fogr & & & & & $\begin{array}{l}.4392 \\
{[.2715]}\end{array}$ & & & \\
\hline nword & & & & & & & & $\begin{array}{l}.2404 * * * \\
{[.0918]} \\
\end{array}$ \\
\hline nparag & & & & & & $\begin{array}{l}.2686 * * * * \\
{[.07585]}\end{array}$ & & \\
\hline nsent & & & & & & & $\begin{array}{l}.2769 * * * \\
{[.0877]}\end{array}$ & \\
\hline cut_1 & -10.3413 & -10.5433 & -11.8940 & -12.1052 & -11.214 & -9.877 & -9.5021 & -8.9787 \\
\hline cut_2 & -8.8186 & -9.0205 & -10.3679 & -10.5785 & -9.6897 & -8.3460 & -7.9734 & -7.452 \\
\hline Pseudo R2 & 0.3198 & 0.3199 & 0.3207 & 0.3208 & .3203 & 0.3219 & 0.3215 & 0.3210 \\
\hline AIC Statistic & .9430 & .9434 & .9423 & .9421 & .9429 & .9406 & .9412 & .9419 \\
\hline
\end{tabular}

Source: Own calculations in Stata 
In specifications 2-5 (models 2-5) we investigate the relevance of the readability of project descriptions. According to our analysis (model 3 and model 4) FOG text (FOGTXT) at the level of 5\%, as well as FOG dictionary index (FOGDCT) at the level of 10\%, are statistically significant and have the expected sign, meaning that a more difficult project's description decreases the chance of the funding success. The different explanation power of those measures may be related to the fact, that the Polish language uses many forms thus the textual fog index may be a better measure of text readability.

Furthermore, in the specification 2 (model 2) we checked the significance of the text index classifying the project's description up to 7 categories in terms of its difficulty, and in specification 5 (model 5) we analyzed the FOGR index including rarely used words. Both variables obtained the expected sign, however are not significant, which confirms the results of the U Mann-Whitney test. We explain this result by the fact that overall, the crowdfunding campaigns in the underlying sample, have high readability in this measure (i.e. have lower scores in FOGR) and rare words are not often used in the description. Moreover, in respect to the text index, the relatively low number of classes (seven) means that they cover wide range of descriptions regarding the text readability.

In specifications 6-8 (model 6-8) we include variables describing the information quantity of the project description. In line with the literature, all three variables: number of words, sentences, and paragraphs significantly influence the success of the campaigns and obtain the expected sign. In crowdfunding, shorter description increases the chance of reaching the declared funding goal.

\section{Conclusion}

Despite the growing interest in crowdfunding, the success rate on the largest crowdfunding platforms is still estimated below 50 percent. Thus, one of the main research areas on crowdfunding is devoted to its success determinants. By using a database of over 2,800 crowdfunding projects registered on one of the largest platforms in Poland we investigated the relation between the language antecedents and crowdfunding success. Based on the unimodel theory of persuasion we identified variables related to the quantity dimension of the crowdfunding campaign's description, i.e. the length of the text as well as the quality dimension, i.e. the text readability.

This paper contributes to the crowdfunding literature in several ways. To the best of our knowledge this paper is among the first to explore the relation between language antecedents and crowdfunding success in a language different than English. Moreover, this research sheds some light on the importance of crowdfunding projects' descriptions. Our results show that longer text increases the chance of the funding success, it also leads to decreasing the information asymmetry and provides a more detailed campaign description. In the analysis, the length of the text was measured by the number of words, sentences and paragraphs in order to provide the consistency of the obtained results. Our results are in line with results obtained by Lagazio and Querci, Koch and Siering (2018).

Moreover, in line with the theory of persuasion, we prove that the text readability is positively related to the crowdfunding success. We argue that, despite the fact, that projects' descriptions in the sample are relatively easy to understand, the readability is still an important success determinant. In the reward-based model crowdfunding, the supporters usually donate small amounts of money, thus a complex and difficult description may seem discouraging. In our sample, the average contribution per supporter is less than 90 PLN (about USD 23). We assume that due to the small amount, the backers are willing to spend less time analyzing the project and the description. 
Similar to other papers devoted to crowdfunding success determinants, our research has several limitations. One of them is the fact that the analysed data comes from one crowdfunding platform, however, it is the biggest one operating in Poland and the sample is large enough to enable statistical inference. In future research we would like to include variables referring to the content of the video uploaded on the campaign's website. In our opinion, its content might be more important to potential supporters than the project description itself.

\section{Acknowledgement}

No external funds were used for this research.

\section{References}

Agrawal, A. K., Catalini, C., \& Goldfarb, A. (2011). The geography of crowdfunding. National Bureau of Economic Research, w16820.

Bańko, M. (2009). Wyktady z polskiej fleksji. Warszawa: Wydawnictwo Naukowe PWN.

Bartmiński, J., \& Niebrzegowska-Bartmińska, S. (2010). Tekstologia. Warszawa: Wydawnictwo Naukowe PWN.

Beier, M., \& Wagner, K. (2015). Crowdfunding success: A perspective from social media and e-commerce. Paper presented at the Thirty Sixth International Conference on Information Systems, Fort Worth.

Björnsson, C. H. (1983). Readability of newspapers in 11 languages. Reading Research Quarterly, 18(4), 480-497.

Charzyńska, E., Dębowski Ł., Gruszczyński W., \& Hadryan M. (2015). Historia badań nad zrozumiałością tekstu. In Gruszczyński, W., Ogrodniczuk, M. (Eds.). Jasnopis czyli mierzenie zrozumiałości polskich tekstów użytkowych (pp. 11-37). Warszawa: SWPS Uniwersytet Humanistycznospołeczny.

Colombo, M. G., Franzoni, C., Rossi-Lamastra, C. (2015). Internal social capital and the attraction of early contributions in crowdfunding. Entrepreneurship Theory and Practice, 39(1), 75-100.

Cordova, A., Dolci, J., \& Gianfrate, G. (2015). The determinants of crowdfunding success: evidence from technology projects. Procedia - Social and Behavioral Sciences, 181, 115124.

da Cruz, J.V. (2018). Beyond financing: Crowdfunding as an informational mechanism. Journal of Business Venturing, 33(1), 371-393.

Dębowski Ł., Broda B., Nitoń B., \& Charzyńska E. (2015). Jasnopis - A Program to Compute Readability of Texts in Polish Based on Psycholinguistic Research. In B. Sharp, Lubaszewski W., Delmonte R. (Eds.) Natural Language Processing and Cognitive Science, 51-61.

Flesch, R. (1948). A new readability yardstick. Journal of Applied Psychology, 32, 221-233.

Gruszczyński, W., Broda, B., Charzyńska, E., Dębowski, Ł., Hadryan, M., Nitoń, B., \& Ogrodniczuk, M. (2014). Measuring Readability of Polish Texts. Baseline Experiments. Paper presented at the Ninth International Conference on Language Resources and Evaluation. Reykjavik, Iceland.

Gruszczyński, W., \& Hadryan, M. (2015). Cechy tekstu trudnego. In Gruszczyński, W., Ogrodniczuk M., (Eds.), Jasnopis czyli mierzenie zrozumiałości polskich tekstów użytkowych (pp. 39-76). Warszawa: SWPS Uniwersytet Humanistycznospołeczny.

Gunning, R. (1952). The Technique of Clear Writing. New York: McGraw-Hill. 
Hiebert, H. E. (2011, June). Using Multiple Sources of Information in Establishing Text Complexity. Reading Research Report, 11.03, University of California, Santa Cruz: TextProject Inc.

Jasnopis Application at: http://jasnopis.pl/aplikacja\#

Kazai, G. (2011). In search of quality in crowdsourcing for search engine evaluation. Computer Science, 6611, 165-176.

Koch, J. A., \& Siering, M. (2015). Crowdfunding success factors: The characteristics of successfully funded projects on crowdfunding platforms. Paper presented at the TwentyThird European Conference on Information Systems (ECIS), Münster, Germany.

Kraus, S., Richter, C., Brem, A., Cheng, C.F., \& Chang, M.L. (2016). Strategies for rewardbased crowdfunding campaigns. Journal of Innovation \& Knowledge, 1(1), 13-23.

Kruglansky, A.W. (1989). Ly epistemics and human knowledge: cognitive and motivational bases. New York: Plenum.

Kruglansky, A.W. (2004). The psychology of closed-mindedness. New York: Psychology Press.

Kruglanski, A. W., Chen, X., Pierro, A., Mannetti, L., Erb, H. P., \& Spiegel, S. (2006). Persuasion according to the unimodel: Implications for cancer communication. Journal of Communication, 56, 105-122.

Kuppuswamy, V., \& Bayus, B.L. (2017). Does my contribution to your crowdfunding project matter?. Journal of Business Venturing, 32(1), 72-89.

Lagazio, C., \& Querci, F. (2018). Exploring the multi-sided nature of crowdfunding campaign success. Journal of Business Research, 90, 318-324.

Laswell, H.D. (1948). The structure and function of communication in society, The Communication of Ideas. New York: Harper and Brothers.

Lively, B. A., \& Pressey, S. L. (1923). A method for measuring the "vocabulary Burden" of textbooks. Educational Administration and Supervision, 9, 389-398.

Lorge, I. (1944). Predicting readability. Teachers College Record, 45, 404-419.

Luo, X., \& Luo, B. (2017). Research on Environmental Crowdfunding Projects Based on Narrative Persuasion Theory. European Journal of Business and Management, 9 (33), 99-105.

Makowski, M. (2013). Niewerbalna komunikacja $w$ reklamie telewizyjnej. Zastosowanie $i$ oddziatywanie. Warszawa: CeDeWu.pl

McGuire, W. J. (1968). Personality and attitude change: An information processing theory. In Greenwald, A.G., Brock, T.C., Ostrom, T.M., (Eds) Psychological foundations of attitudes (pp. 171-196) San Diego, CA: Academic Press.

McGuire, W. J. (1985). Personality and attitude change. In Lindzey, G., Aronson, E. (Eds) Handbook of Social Psychology (ed. 3, vol. 2, pp.233-346). New York: Random House.

Mitra, T., \& Gilbert, E. (2014, February). The language that gets people to give: Phrases that predict success on Kickstarter. Paper presented at the 17th ACM conference on Computer supported cooperative work \& social computing, Baltimore, Maryland, USA.

Mollick, E. (2014). The dynamics of crowdfunding: an exploratory study. Journal of Business Venturing, 29(1), 1-16.

Moy N., Chan H. F., Torgler B. (2018). How much is too much? The effects of information quantity on crowdfunding performance. PloS One, 13(3), 1-15.

Mrzygłód U., Skurczyński M., \& Adamska-Mieruszewska J. (2018). Raising money on crowdfunding platforms: the components of success. Paper presented at the CrossCultural Business Conference, Steyr.

Pancer, E., Chandler, V., Poole, M., \& Noseworthy, T.J. (2018). How Readability Shapes Social Media Engagement. Journal of Consumer Psychology, 29(2), 262-270.

Patty, W. W., \& Painter, W. I. (1931). A technique for measuring the vocabulary burden of textbooks. The Journal of Educational Research, 24(2), 127-134. 
Petty, R. E., \& Briñol, P. (2010). Attitude change. In Baumaister, R. F., Finkel, E. J. (Eds.) Advanced social psychology. The State of the Science (pp. 217-259). New York: Oxford University Press Inc.

Petty, R. E., \& Cacioppo, J. T. (1986). The elaboration likelihood model of persuasion. In Communication and persuasion (pp. 1-24). New York: Springer.

Pietraszkiewicz, A., Soppe, B., \& Formanowicz, M. (2017). Go pro bono. Social Psychology, 48 (5), 265-278.

Poshalian, S., \& Crissy, W. J. (1952). Corporate annual reports are difficult, dull reading, human interest value low, survey shows. Journal of Accountancy (pre-1986), 94(000002), 215-228.

Shneor, R., \& Vik, A. A. (2020). Crowdfunding success: a systematic literature review 20102017. Baltic Journal of Management, 15(2), 149-182.. doi:10.1108/BJM-04-2019-0148.

Tafesse, W. (2021). Communicating crowdfunding campaigns: How message strategy, vivid media use and product type influence campaign. Journal of Business Research, 127, 252263.

Vogel, M., \& Washburne, C. (1928). An objective method of determining grade placement of children's reading material. The Elementary School Journal, 28(5), 373-381.

Vukovic, M., Mariana, L., \& Laredo, J. (2009). People cloud for the globally integrated enterprise. In Asit, D., Gittler, F., Tourmani, F. (Eds.), Service-oriented computing (pp.109-114). Berlin: Springer.

Wang, W., Chen, W., \& Wang, H. (2020). Emphasizing the entrepreneur or the idea? The impact of text content emphasis on investment decisions in crowdfunding. Decission Support Systems, 136.

Wang, N., Li, Q., Liang, H., Ye, T., \& Ge, S. (2018). Understanding the importance of interaction between creators and backers in crowdfunding success. Electronic Commerce Research and Applications, 27, 106-117.

Wierzbicka, A. (1985). Different cultures, different languages, different speech acts: Polish vs. English. Journal of pragmatics, 9(2-3), 145-178.

Wierzbicka, A. (1997). Understanding cultures through their key words: English, Russian, Polish, German, and Japanese. Oxford Studies in Anthropological Linguistics, Vol. 8.

Wojciszke, B. (2002). Człowiek wśród ludzi. Zarys psychologii społecznej. Warszawa: Wydawnictwo Naukowe Scholar.

Xu, A., Yang, X., Rao, H., Fu, W. T., Huang, S. W., \& Bailey, B. P. (2014). Show me the money! An analysis of project updates during crowdfunding campaigns. Paper presented at the SIGCHI conference on human factors in computing systems.

Zhao L., \& Ryu S. (2020). Reward-based crowdfunding research and practice. In: Shneor R., Zhao L., Flåten BT. (eds) Advances in Crowdfunding. Palgrave Macmillan, Cham. https://doi.org/10.1007/978-3-030-46309-0_6

Zhou, M. J., Lu, B., Fan, W. P., \& Wang, G. A. (2018). Project description and crowdfunding success: an exploratory study. Information Systems Frontiers, 20(2), 259-274.

Ziegler, T., Shneor, R., \& Wenzlaff, K. (2020). The Global Alternative Finance Benchmarking Report. Cambridge, UK: Cambridge Centre for Alternative Finance. 